Article

\title{
Benzalkonium Chloride Induces a VBNC State in Listeria monocytogenes
}

\author{
Matthias Noll ${ }^{1, * \mathbb{D}}$, Katharina Trunzer ${ }^{1}$, Antje Vondran ${ }^{1}$, Szilvia Vincze ${ }^{2}$, Ralf Dieckmann ${ }^{2}$, \\ Sascha A1 Dahouk ${ }^{2}$ (D) and Carolin Gold ${ }^{1}$ \\ 1 Institute for Bioanalysis, Department of Applied Sciences, Coburg University of Applied Sciences and Arts, \\ Friedrich-Streib-Straße 2, D-96450 Coburg, Germany; Katharina.trunzer@hs-coburg.de (K.T.); \\ Antje.vondran@hs-coburg.de (A.V.); gold.car@t-online.de (C.G.) \\ 2 German Federal Institute for Risk Assessment, Max-Dohrn-Str. 8-10, 10589 Berlin, Germany; \\ Szilvia.Vincze@bfr.bund.de (S.V.); Ralf.Dieckmann@bfr.bund.de (R.D.); Sascha.Al-Dahouk@gmx.de (S.A.D.) \\ * Correspondence: Matthias.noll@hs-coburg.de; Tel.: +49-09561-317645
}

Received: 22 December 2019; Accepted: 23 January 2020; Published: 28 January 2020

\begin{abstract}
The objective of our study was to investigate the effects of benzalkonium chloride (BC) adaptation of L. monocytogenes on the susceptibility to antimicrobial agents and on the viable but non culturable (VBNC) state of the bacterial cells. We adapted L. monocytogenes SLCC2540 to BC by applying $\mathrm{BC}$ below minimum inhibitory concentration (MIC) to above minimum bactericidal concentration (MBC). The culturable fractions and the susceptibility of adapted and parental cells to $\mathrm{BC}$ were assessed. In addition, cell membrane permeability and glucose uptake were analyzed by multi parametric flow cytometry using the fluorescent agents SYTO9, propidium iodide, and 2-deoxy-2-[(7-nitro-2,1,3-benzoxadiazol-4-yl)amino]-D-glucose (2-NBDG). Adapted cells displayed a two-fold MIC increase of BC and reduced antibiotic susceptibility. At high BC concentrations, the decrease in the number of colony forming units was significantly lower in the population of adapted cells compared to parental cells. At the same time, the number of metabolically active cells with intact membranes was significantly higher than the number of culturable cells. Growth-independent viability assays revealed an adapted subpopulation after BC application that was not culturable, indicating increased abundance of viable but nonculturable (VBNC) cells. Moreover, adapted cells can outcompete non-adapted cells under sublethal concentrations of disinfectants, which may lead to novel public health risks.
\end{abstract}

Keywords: 2-NBDG; antibiotic susceptibility; benzalkonium chloride; colony forming units; flow cytometry; Listeria monocytogenes; metabolic activity; viable but nonculturable; VBNC

\section{Introduction}

Listeria monocytogenes is a ubiquitous, Gram-positive, facultative intracellular opportunistic pathogen and the causative agent of human listeriosis, a disease with a wide variety of clinical presentations ranging from mild fever to meningoencephalitis with lethal outcome. Populations at highest risk for invasive listeriosis include elderly and immunocompromised persons, and pregnant women and their newborns [1]. The incubation period of listeriosis may be long (median 11 days, range $0-70$ days) [1]. Listeria monocytogenes is usually transmitted by the consumption of contaminated food [2,3], and various foodstuffs have been identified as vehicles [2,4-6]. Adverse conditions may induce tolerance or resistance towards environmental stress factors and/or a shift in L. monocytogenes from a culturable state to a viable but nonculturable state (VBNC) [7]. VBNC cells are defined as bacterial cells that do not form colonies on standard culture media but still retain metabolic activity [8] and may revert to the active state [9]. Early VBNC studies coupled bacterial culture with microscopic counting 
of stained cells using SYTO 9/propidium iodide (SYTO9/PI), 5-cyano-2,3-ditolyl tetrazolium chloride (CTC), 4' ,6-diamidino-2-phenylindole (DAPI), and/or fluorescently labelled antibodies [7,10-12]. Recent studies expanded the methodological approaches to determine the metabolic activity and cell membrane integrity of VBNC cells by ATP determination [13], quantitative PCR combined with propidium monoazide treatment [14], the capability to ferment sugars after reuptake [13], and flow cytometric analyses coupled with cell staining [15]. Flow cytometric analysis of SYTO9/PI was also linked to the uptake activity of 2-deoxy-2-[(7-nitro-2,1,3-benzoxadiazol-4-yl)amino]-D-glucose (2-NBDG) to assess both cell membrane integrity and metabolic activity simultaneously [16], thereby quantifying VBNC bacteria at the single cell level [17]. Various stress conditions have been identified to induce the VBNC state in L. monocytogenes, including chlorine-based sanitizing treatments [15] and non-ionic surfactants combined with inorganic salts [13].

Quaternary ammonium compounds (QACs), such as benzalkonium chloride (BC), are widely used as biocides for the disinfection of surfaces, including food production environments [18,19]. The alkyl chain of QACs perturbs and disrupts the microbial membrane bilayer and its charge distribution [20]. Microbial mechanisms of tolerance and resistance towards QACs include changes in the overall membrane composition, downregulation of porins, overexpression or modification of efflux pumps, horizontal gene transfer of resistance-associated genes, biofilm formation, and biodegradation of QACs [18]. Exposure of L. monocytogenes to progressively increasing BC concentrations frequently leads to BC adaptation, which can often be attributed to shifts in the efflux pump activity $[19,21,22]$. However, how BC adaptation affects the VBNC state and the metabolic activity of L. monocytogenes has not been addressed so far.

Therefore, the aims of our study were to investigate the effects of $B C$ adaptation in L. monocytogenes on (i) susceptibility to antimicrobial agents (BC and antibiotics), (ii) culturability, and (iii) metabolic activity.

\section{Materials and Methods}

\subsection{Listeria monocytogenes Isolate under Study and Biocide Susceptibility Testing}

Listeria monocytogenes SLCC2540 was investigated in this study. It was isolated from human in the USA in 1956 and belonged to serotype 3b. Minimum inhibitory (MIC) and minimum bactericidal concentrations (MBC) were determined in nine independent replicates, as previously outlined [23] with minor modifications. Brain heart infusion broth (BHI) (Carl Roth $\mathrm{GmbH}$, Karlsruhe, Germany) was utilized, and the cell density of the inoculum was adjusted to approx. $2 \times 10^{8}$ cells $\mathrm{mL}^{-1}$. Dey-Engley neutralizing broth (Sigma-Aldrich KGaA, Darmstadt, Germany) was used to quench biocidal effects for MBC testing [23]. A stock solution of $4 \mathrm{mg} \mathrm{mL}^{-1} \mathrm{BC}$ (Sigma Aldrich) was prepared freshly by dissolving $0.02 \mathrm{~g}$ of $\mathrm{BC}$ in $5 \mathrm{~mL}$ of sterile distilled water.

\subsection{Adaptation to Benzalkonium Chloride}

For bacterial adaptation, L. monocytogenes SLCC2540 was cultivated by serial passages in $200 \mu \mathrm{L}$

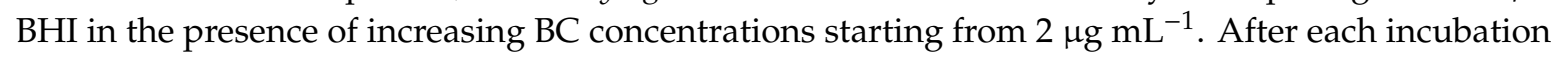
cycle of $24 \mathrm{~h}$, the optical density (OD) was measured at a wavelength of $595 \mathrm{~nm}$ after $5 \mathrm{~s}$ of shaking using a FLUOstar OMEGA microplate reader (BMG Labtech, Ortenberg, Germany). The empty value (microtiter well containing biocide solution and BHI without L. monocytogenes) was subtracted from measured data, and a $\Delta \mathrm{OD}_{595 \mathrm{~nm}}$ of 0.1 was considered as the cutoff value for bacterial growth, if growth control (microtiter without biocide in solution and BHI with L. monocytogenes) had a $\Delta \mathrm{OD}_{595 \mathrm{~nm}}>0.4$. When bacterial growth was observed, strain SLCC2540 was subcultured in identical BC concentrations or stepwise (by $1 \mu \mathrm{g} \mathrm{mL}^{-1}$ ) increasing $\mathrm{BC}$ concentrations until growth inhibition was achieved. The stability of biocide tolerance was tested after 15 subcultures of the adapted strain. Parent and adapted strains were stored in BHI broth supplemented with $15 \%$ glycerol (Carl Roth) at $-80^{\circ} \mathrm{C}$. 


\subsection{Determination of Culturable Cells after BC Exposure}

Parent and adapted L. monocytogenes strains (inoculum: $2 \times 10^{8}$ cells $\mathrm{mL}^{-1}$ ) were incubated and gently shaken in $200 \mu \mathrm{L}$ BHI without BC and in BHI supplemented with $B C$ concentrations of 2, 3, 4, 5, $6,8,9,10,11,12$, and $13 \mu \mathrm{g} \mathrm{mL} \mathrm{m}^{-1}$ at $37^{\circ} \mathrm{C}$ for $24 \mathrm{~h}$. Colony forming units (CFUs) were determined in nine replicates according to the standard protocol of ISO 11290 [24].

\subsection{Antibiotic Susceptibility Testing and Flow Cytometric Analysis}

Parent and adapted L. monocytogenes SLCC2540 cells were incubated in a range of BC concentrations $\left(0,2,3,4,5,6,8,9,10,11,12\right.$, and $\left.13 \mu \mathrm{g} \mathrm{mL}{ }^{-1}\right)$ at $37^{\circ} \mathrm{C}$ for $24 \mathrm{~h}$. All experiments were conducted in biologically independent triplicates. A total of $1.5 \mathrm{~mL}$ of each liquid culture was centrifuged at $10,000 \times \mathrm{g}$ at $4{ }^{\circ} \mathrm{C}$ for $5 \mathrm{~min}$. Afterwards, cells were washed three times with sterile filtered phosphate buffered saline (PBS; $8 \mathrm{NaCl} \mathrm{gL}-1,0.2 \mathrm{KCl} \mathrm{gL}{ }^{-1}, 1.44 \mathrm{Na}_{2} \mathrm{HPO}_{4} \mathrm{gL}^{-1}, 0.24 \mathrm{KH}_{2} \mathrm{HPO}_{4} \mathrm{gL}^{-1}$; $\mathrm{pH}$ 7.4) and finally resuspended in $1.5 \mathrm{~mL}$ PBS. Each sample was divided into four aliquots. The first fraction was used to test the antibiotic susceptibility towards 14 different antibiotics, as previously described [25], using BHI broth instead of H-medium. The remaining three fractions were analyzed by flow cytometry. One aliquot was stained with PI (LIVE/DEAD BacLight kit for flow cytometry, Fisher Scientific, Schwerte, Germany), another one with SYTO9 (Life Technologies GmbH, Darmstadt, Germany), and the last one with the fluorescence labelled glucose analogue 2-NBDG (Life Technologies) modified according to Berney et al. [16]. Briefly, flow cytometry was performed using a NovoCyte Flow Cytometer (Acea Biosciences Inc., San Diego, CA, USA) at an excitation wavelength of $488 \mathrm{~nm}$. A photomultiplier with a band pass filter of $530 / 20 \mathrm{~nm}$ was used to collect the green fluorescence of SYTO9 and 2-NBDG, while the red fluorescence of PI was detected using a band pass filter of 615/20 nm. Preliminary studies on L. monocytogenes strain SLCC2540, not exposed to BC, revealed linear uptake kinetics when $<5 \times 10^{9}$ cells mL ${ }^{-1}$ were incubated with $10 \mu \mathrm{M}$ 2-NBDG for $15 \mathrm{~min}$ at $37^{\circ} \mathrm{C}$. Data obtained from each channel were displayed in logarithmic scale and analyzed using the Novo Express software 1.2 (Acea Biosciences Inc.). For each sample, we collected parameters of 300,000 events at a flow rate of 3000 events s${ }^{-1}$. The respective volume was documented to receive the amount of events per $\mathrm{mL}$, namely flow cytometric cell counts.

L. monocytogenes strain SLCC2540 incubated in BHI to logarithmic growth phase served as viable positive control, while cells heated at $95^{\circ} \mathrm{C}$ for $10 \mathrm{~min}$ were used as non-viable negative control. Cell densities of both controls were set to $2 \times 10^{8}$ cells $\mathrm{mL}^{-1}$ in PBS. Controls were used to evaluate the uptake kinetics of PI, SYTO9, and 2-NBDG and for adjusting quadrants. Quadrants were associated with physiological properties such as cell membrane integrity (intact: SYTO9 positive but PI negative; not intact: SYTO 9 positive and PI positive) and metabolic activity (active: 2-NBDG positive; inactive: 2-NBDG negative). Glucose uptake rates of parent and adapted L. monocytogenes cells were calculated by dividing fluorescence intensity of 2-NBDG by total cell count in each sample. Mean values and standard deviations are presented.

\subsection{Statistics}

Statistical analyses were performed to evaluate significant differences between adapted and parent L. monocytogenes SLCC 2540 cells as well as between CFUs and cytometric counts of stained cells using $\mathrm{R}$ software [26]. Two way-analysis of variance (ANOVA) and Tukey's post-hoc test were performed using Origin 2017 (OriginLab Corporation, Northampton, MA, USA). The significance level was set to $p \leq 0.05$.

\section{Results}

\subsection{Adapted L. monocytogenes Cells Show Shifts in MICs of BC and Some Antibiotics}

In pretests, the neutralizer used for $\mathrm{MBC}$ determination proved to be effective for $\mathrm{BC}$ and was not toxic to L. monocytogenes (data not shown). Susceptibility testing of L. monocytogenes SLCC2540 
revealed a MIC of $4 \mu \mathrm{g} \mathrm{mL}^{-1}$ and a MBC of $11 \mu \mathrm{g} \mathrm{mL}-1$. After adaptation to BC, the adapted cells exhibited a MIC of $8 \mu \mathrm{g} \mathrm{mL}{ }^{-1}$, while the MBC was still the same. The susceptibility profile of the adapted cells remained stable following fifteen subcultures.

CFUs were determined to investigate the fraction of culturable cells. For the original strain SLCC2540 (parent cells), CFUs increased compared to the starting inoculum during growth in BHI without BC and with BC below MIC concentrations (Figure 1A). Incubation of SLCC2540 in BHI with $\mathrm{BC}$ concentrations above MIC resulted in a reduced number of CFUs. For adapted cells, the CFU counts showed a similar pattern as for the parent cells during incubation in sub-inhibitory BC concentrations. Nonetheless, the CFUs of adapted cells were higher compared to parent cells after incubation in BHI, with $\mathrm{BC}$ concentrations ranging between 6 and $9 \mu \mathrm{g} \mathrm{mL} L^{-1}$.
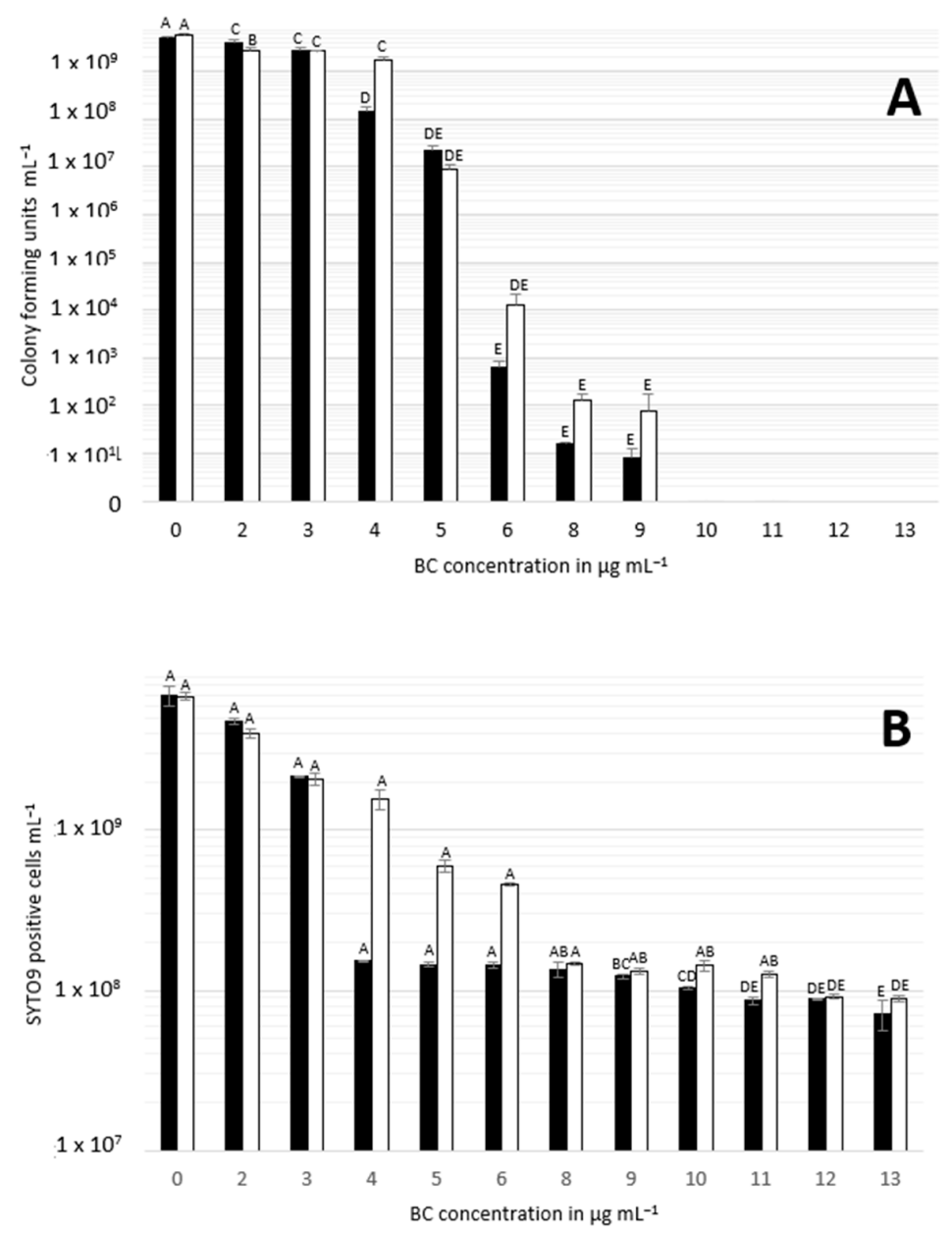

Figure 1. Colony forming units (A) and SYTO9-positive cells (B) of parent (black bars) and adapted (white bars) Listeria monocytogenes SLCC2540 following cultivation in brain heart infusion broth (BHI) containing benzalkonium chloride (BC) in various concentrations. Error bars indicate standard deviation of nine replicates. Different letters above bars within panels indicate significant differences $(p<0.05)$ according to two-way analysis of variance (ANOVA).

Total flow cytometric cell counts of SYTO9-positive cells were higher at sub-inhibitory concentrations compared to the primary inoculum for both cell types (Figure 1B). At concentrations equal to or higher than the respective MIC of BC, the total number of cells resembled the initial inoculum.

Adapted cells showed a reduced susceptibility to certain antibiotics, mainly ceftriaxone, gentamicin, linezolid, tetracycline, and trimethoprim/sulfamethoxazole, compared to parent cells (Table 1). Moreover, the increase in antibiotic susceptibility with increasing $\mathrm{BC}$ concentrations was less pronounced in adapted cells compared to parent cells. 
Table 1. Antibiotic susceptibility profiles of adapted (A) and parent (B) Listeria monocytogenes SLCC2540 cells after growth in BHI supplemented with benzalkonium chloride (BC). Differences in the susceptibility profiles of adapted and parent cells are highlighted in bold. Antibiotics are AMP, ampicillin; PEN, benzylpenicillin; CRO, ceftriaxone; CIP, ciprofloxacin; DPT, daptomycin; ERY, erythromycin; GEN, gentamicin; LIZ, linezolid; MER, meropenem; RIF, rifampicin; TET, tetracycline; TGC, tigecycline; T/S, trimethoprim/sulfamethoxazole; VAN, vancomycin.

\begin{tabular}{|c|c|c|c|c|c|c|c|c|c|c|c|c|c|c|}
\hline \multirow[b]{2}{*}{ VAN } & \multicolumn{10}{|c|}{ Minimum Inhibitory Concentrations in $\mu \mathrm{g} \mathrm{mL}^{-1}$} & \multicolumn{4}{|c|}{ A } \\
\hline & $\mathrm{T} / \mathrm{S}$ & TGC & TET & RIF & PEN & MER & LIZ & GEN & ERY & DPT & CRO & CIP & AMP & $\mathrm{BC}\left[\mu \mathrm{g} \mathrm{mL}^{-1}\right]^{1}$ \\
\hline 1 & $0.0625 / 1.1875$ & 0.0625 & 1 & 0.125 & 0.25 & 0.5 & 2 & 2 & $<0.25$ & 16 & 128 & 4 & 0.25 & 0 \\
\hline$<1$ & $0.0625 / 1.1875$ & 0.0625 & 0.5 & 0.125 & 0.125 & 0.125 & 1 & 2 & $<0.25$ & 16 & 128 & 4 & 0.25 & 1 \\
\hline$<1$ & $0.0625 / 1.1875$ & 0.0625 & 0.25 & 0.0625 & 0.0625 & 0.0625 & 0.5 & 0.5 & $<0.25$ & 16 & 64 & 1 & 0.125 & 2 \\
\hline \multirow[t]{2}{*}{$<1$} & $0.03125 / 0.59375$ & $<0.03125$ & $<0.25$ & $<0.0625$ & $<0.0625$ & $<0.0625$ & $<0.5$ & $<0.5$ & $<0.25$ & $<0.5$ & $<1$ & $<0.25$ & $<0.0625$ & 3 \\
\hline & \multicolumn{10}{|c|}{ Minimum Inhibitory Concentrations in $\mu \mathrm{g} \mathrm{mL}^{-1}$} & \multicolumn{4}{|c|}{ B } \\
\hline VAN & $\mathrm{T} / \mathrm{S}$ & TGC & TET & RIF & PEN & MER & LIZ & GEN & ERY & DPT & CRO & CIP & AMP & $\mathrm{BC}\left[\mu \mathrm{g} \mathrm{mL}^{-1}\right]^{1}$ \\
\hline 1 & $<0.03125 / 0.59375$ & 0.0625 & 0.5 & 0.25 & 0.25 & 0.5 & 1 & 1 & $<0.25$ & 16 & 64 & 4 & 0.25 & 0 \\
\hline$<1$ & $<0.03125 / 0.59375$ & $<0.03125$ & $<0.25$ & 0.0625 & 0.0625 & 0.125 & 0.5 & $<0.5$ & $<0.25$ & 4 & 16 & 0.5 & 0.25 & 1 \\
\hline$<1$ & $<0.03125 / 0.59375$ & $<0.03125$ & $<0.25$ & $<0.0625$ & 0.0625 & $<0.0625$ & $<0.5$ & $<0.5$ & $<0.25$ & $<0.5$ & 1 & $<0.25$ & $<0.0625$ & 2 \\
\hline
\end{tabular}




\subsection{Adaptation Increased the Proportion of Cells with Intact Membranes at high BC Concentrations}

The proportion of cells with intact membranes was determined by calculating the ratio of SYTO9-positive and PI-negative cells [16,17]. Between $80 \%$ and $100 \%$ of parent and adapted cells were intact after cultivation in BHI without and supplemented with up to $6 \mu \mathrm{g} \mathrm{mL}^{-1} \mathrm{BC}$ (Figure 2, supplementary Figure S1A). At higher BC concentrations (8 to $11 \mu \mathrm{g} \mathrm{mL}^{-1}$ ), the proportion of intact cells was significantly higher for adapted cells compared to parent cells.

\subsection{Adapted Cells Maintain Metabolic Activity at High BC Concentrations}

To quantify metabolic activity of L. monocytogenes after biocide exposure, we analyzed 2-NBDG uptake rates of parent as well as adapted cells following cultivation in BHI supplemented with BC. 2-NBDG uptake was similar in parent and adapted cells when incubated in BC concentrations below the respective MICs. While the number of metabolically active cells decreased for the parent strain at $\mathrm{BC}$ concentrations $>4 \mu \mathrm{g} \mathrm{mL} L^{-1}$, their number remained high in the adapted strain up to $11 \mu \mathrm{g} \mathrm{mL}-1$ BC (Figure 3, supplementary Figure S1B).

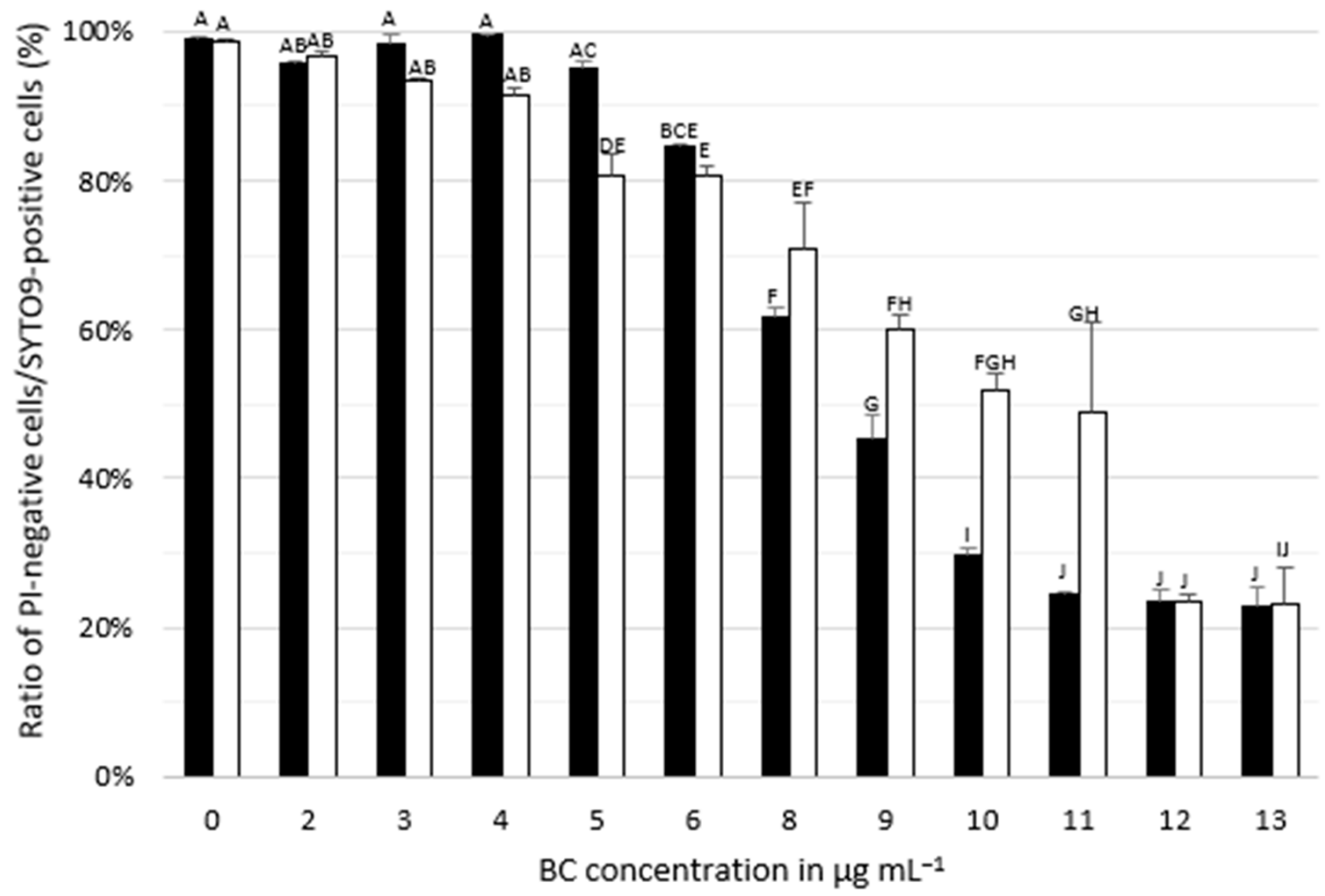

Figure 2. Mean ratio of PI-negative to SYTO9-positive parent (black bars) and adapted (white bars) Listeria monocytogenes SLCC2540 cells following cultivation in BHI containing benzalkonium chloride (BC) in various concentrations. SYTO9-positive cells are indicative of total cell counts, while PI-negative cells are a surrogate for intact cell membranes. Error bars indicate the standard deviation of three replicates. Different letters above bars within panels represent significant differences $(p<0.05)$ according to two-way analysis of variance (ANOVA). 
$100 \%$

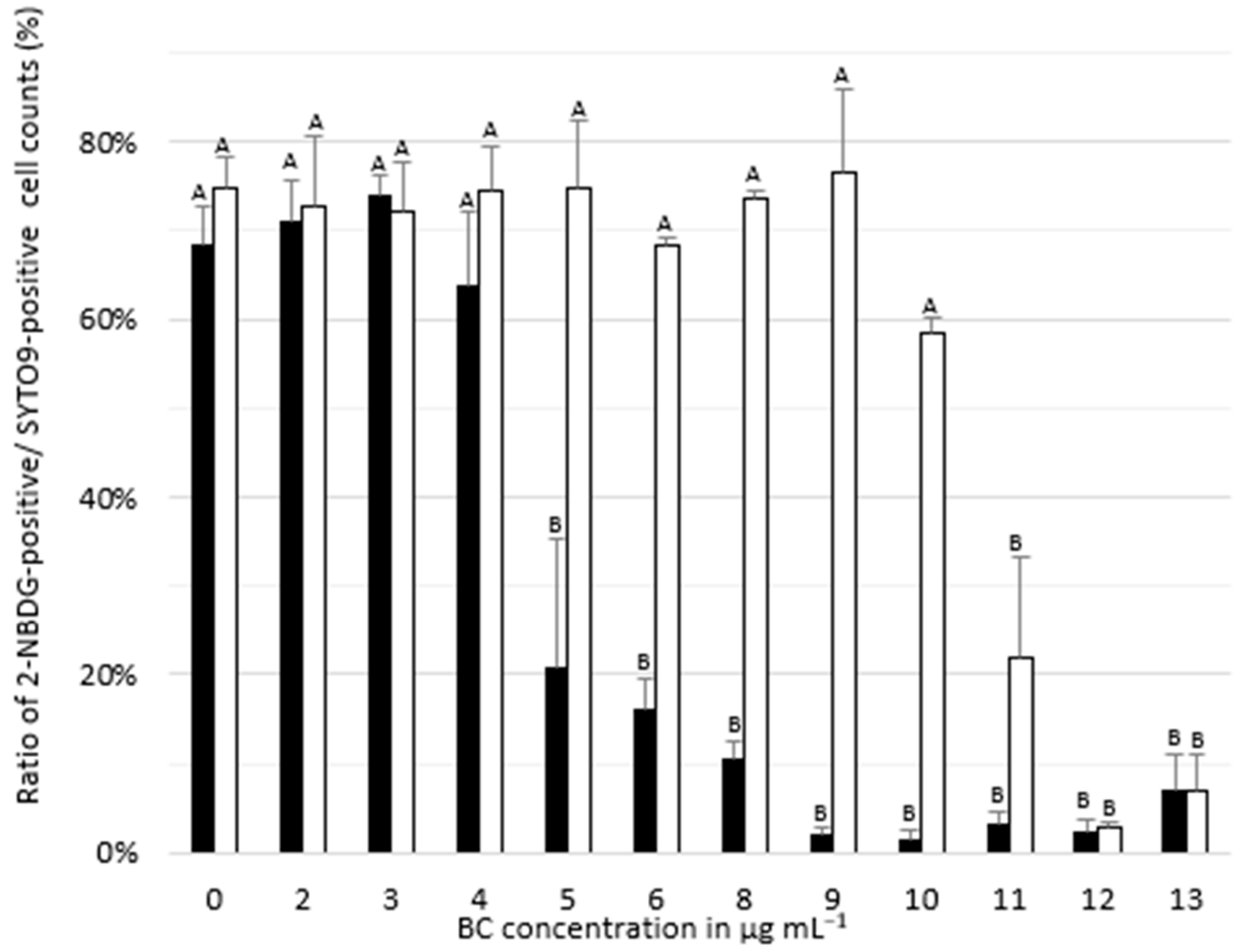

Figure 3. Mean ratio of 2-NBDG-positive to SYTO9-positive parent (black bars) and adapted Listeria monocytogenes SLCC2540 cells (white bars) following cultivation in brain heart infusion broth containing benzalkonium chloride (BC) in various concentrations. 2-NBDG-positive cells are indicative of metabolically active cells, while SYTO9-positive cells represent the total number of cells. Error bars show the standard deviation of three replicates. Different letters above bars within panels indicate significant differences $(p<0.05)$ according to two-way analysis of variance (ANOVA).

\section{Discussion}

Following adaptation to BC, L. monocytogenes SLCC2540 revealed a twofold MIC increase of this biocide compared to parent cells. In previous studies, similar and sometimes larger MIC increases after BC exposure were observed $[22,27,28]$.

In addition, reduced susceptibility to ceftriaxone, gentamicin, linezolid, tetracycline, and the combination of trimethoprim and sulfamethoxazole emerged in BC-adapted cells. The development of reduced antibiotic susceptibility is in line with previous studies showing ciprofloxacin resistance in L. monocytogenes after BC exposure [29]. Rakic-Martinez et al. (2011) found that both the adaptation to ciprofloxacin and BC may induce mutations in efflux pump systems, which are responsible for multidrug resistances [29]. Susceptibility to antibiotics increased after incubation with increasing BC concentrations (Table 1), suggesting that pre-incubation with BC weakened the bacterial cells.

Phenotypic characterization of L. monocytogenes field isolates from German food production plants showed no cross-resistance between $B C$ and antibiotics [23], indicating that regular disinfection measures do not necessarily induce cross-adaptation events. The BC-tolerant phenotype remained stable after multiple sub-cultures in drug-free medium, which has been shown for other L. monocytogenes strains $[27,28]$. This phenomenon suggests that phenotypic changes are most likely based on a genetically determined tolerance mechanism rather than on a short-term phenotypic adaptation. 
Several mechanisms of BC resistance have been recently reviewed [18]. However, the effect of BC adaptation on the development of a VBNC state has not been addressed in L. monocytogenes so far. By using flow cytometry, we were able to show that BC-adapted cells maintained their metabolic activity and intact cell walls in higher numbers than parent cells during cultivation in BHI supplemented with BC concentrations above the MIC of the parent strain. However, only a relatively low number of cells was culturable, indicating that increasing $\mathrm{BC}$ concentrations induced adapted cells to enter the VBNC state.

Flow cytometric analysis has the advantage of allowing markable phenotypic attributes to be visualized at the single cell level with a high precision and sensitivity. We did not detect an effect of BC on the fluorescence properties of PI, SYTO9, or 2-NBDG up to a concentration of $13 \mu \mathrm{g} \mathrm{mL}^{-1}$ (data not shown). The quadrants for the different phenotypic attributes were set by measuring the same cells without $\mathrm{BC}$ stress from the exponential growth phase (proliferating living cells with intact cell membrane integrity and metabolic 2-NBDG uptake activity) before and after heat treatment (dead cells with damaged cell membrane and no 2-NBDG uptake), thereby enabling a differentiation between metabolically active and intact cells from other cells and their quantification. Metabolic activity based on 2-NBDG uptake is commonly presented as a proportion in relation to external standards of dead and living cells $[16,17]$. In our study, controls were directly taken from the exponential growth phase of bacterial cells and therefore the external standard of living cells represented an ideal metabolic state. In contrast, a few cells of our external standard of heat-inactivated dead cells were used as an external standard of dead cells. Quantification of 2-NBDG-positive cells was based on a linear increase of the fluorescence signal as evaluated by living and dead L. monocytogenes cells without contact to BC. The pitfalls and benefits of flow cytometric analysis of bacterial cells after antimicrobial treatments were previously reviewed by Léonard and colleagues [30].

The VBNC state was first described by Xu et al. (1982) for Escherichia coli and Vibrio cholerae [12]. Since then, more than 85 other bacterial species were found to enter the VBNC state [31]. The VBNC state has been reported for a broad phylogenetic diversity, indicating a common prokaryotic mechanism to withstand environmental stress conditions. Chemical stress by sub-optimal $\mathrm{pH}$, ethanol, chlorine, household cleaners, antibiotics, or biocides is able to induce the VBNC state in many bacterial species. Recently, the induction of a VBNC state in L. monocytogenes by household cleaners was analyzed [13]. L. monocytogenes cells almost instantly entered the VBNC state following exposure to a combination of non-ionic surfactants and inorganic salts and thereafter could not be resuscitated [13]. The vast majority of adapted cells in our study were viable and metabolically active but not detectable by standard cultivation techniques. It is alarming that L. monocytogenes cells in VBNC state induced by stress factors comparable to $\mathrm{BC}$ remain infectious [32], indicating an unseen (by cultivation techniques) but potent threat in industrial, clinical, and domestic environments.

\section{Conclusions}

BC induced the VBNC state and reduced antibiotic and BC susceptibility in adapted L. monocytogenes SLCC2540 cells. Selective environmental conditions may facilitate additional adaptations leading to multi-resistant strains. Moreover, adapted cells can outcompete non-adapted cells under sublethal concentrations of disinfectants, which may lead to novel public health risks. Therefore, the prevalence of adaptations to biocides and accompanying shifts in phenotypic features should be monitored over time, especially in high-risk environments, such as food processing plants and hospitals. These surveillance data have to be considered in the indispensable future definitions of biocide breakpoints.

Supplementary Materials: The following are available online at http://www.mdpi.com/2076-2607/8/2/184/s1: Figure S1: Mean cell counts of PI positive (A) and 2-NBDG positive (B) cells for parent (black bars) and adapted (white bars) L. monocytogenes SLCC2540 following cultivation in BHI containing benzalkonium chloride (BC) in various concentrations. Error bars indicate standard deviation of three replicates. 
Author Contributions: Conceptualization: M.N., C.G., K.T., R.D. and S.A.D.; methodology: C.G. and K.T.; validation: M.N., C.G. and A.V.; formal analysis: C.G.; investigation: M.N.; resources: M.N. and S.A.D.; data curation: C.G., M.N., S.V. and R.D.; writing—original draft preparation: M.N.; writing—review and editing: S.V., R.D., A.V., S.A.D.; visualization: C.G.; supervision: M.N., R.D. and S.A.D.; project administration: M.N. and S.A.D.; funding acquisition: M.N. All authors have read and agreed to the published version of the manuscript.

Funding: This research was funded by Bundesinstitut für Risikobewertung, grant number 1329-551.

Acknowledgments: We thank Sonja Bauersachs and Laura Schwab for their excellent technical assistance and Christian Buettner for assistance with statistical analysis.

Conflicts of Interest: The authors declare no conflict of interest.

\section{References}

1. Swaminathan, B.; Gerner-Smidt, P. The epidemiology of human listeriosis. Microbes Infect. 2007, 9, 1236-1243. [CrossRef] [PubMed]

2. Allerberger, F. Listeria: Growth, phenotypic differentiation and molecular microbiology. FEMS Immunol. Med. Microbiol. 2003, 3, 183-189. [CrossRef]

3. Weiler, C.; Ifland, A.; Naumann, A.; Kleta, S.; Noll, M. Incorporation of Listeria monocytogenes strains in raw milk biofilms. Int. J. Food Microbiol. 2013, 161, 61-68. [CrossRef] [PubMed]

4. Buchanan, R.L.; Gorris, L.G.M.; Hayman, M.M.; Jackson, T.C.; Whiting, R.C. A review of Listeria monocytogenes: An update on outbreaks, virulence, dose-response, ecology, and risk assessments. Food Control 2017, 75, 1-13. [CrossRef]

5. McLauchlin, J.; Mitchell, R.T.; Smerdon, W.J.; Jewell, K. Listeria monocytogenes and listeriosis: A review of hazard characterisation for use in microbiological risk assessment of foods. Int. J. Food Microbiol. 2004, 92, 15-33. [CrossRef]

6. Szendy, M.; Westhaeuser, F.; Baude, B.; Reim, J.; Dähne, L.; Noll, M. Controlled release of nisin from Neusilin particles to enhance food safety of sour curd cheese. J. Food Sci. Technol. 2019, 56, 1613-1621. [CrossRef]

7. Besnard, V.; Federighi, M.; Declerq, E.; Jugiau, F.; Cappelier, J.-M. Environmental and physico-chemical factors induce VBNC state in Listeria monocytogenes. Vet. Res. 2002, 33, 359-370. [CrossRef]

8. Oliver, J.D. Formation of viable but nonculturable cells. In Starvation in Bacteria; Kjelleberg, S., Ed.; Springer: Boston, MA, USA, 1993; pp. 239-272. ISBN 978-0-306-44430-2.

9. Lin, H.; Ye, C.; Chen, S.; Zhang, S.; Yu, X. Viable but non-culturable E. coli induced by low level chlorination have higher persistence to antibiotics than their culturable counterparts. Environ. Pollut. 2017, 230, 242-249. [CrossRef]

10. Lindbäck, T.; Rottenberg, M.E.; Roche, S.M.; Rørvik, L.M. The ability to enter into an avirulent viable but non-culturable (VBNC) form is widespread among Listeria monocytogenes isolates from salmon, patients and environment. Vet. Res. 2010, 41, 8. [CrossRef]

11. Dreux, N.; Albagnac, C.; Federighi, M.; Carlin, F.; Morris, C.E.; Nguyen-the, C. Viable but non-culturable Listeria monocytogenes on parsley leaves and absence of recovery to a culturable state. J. Appl. Microbiol. 2007, 103, 1272-1281. [CrossRef]

12. Xu, H.S.; Roberts, N.; Singleton, F.L.; Attwell, R.W.; Grimes, D.J.; Colwell, R.R. Survival and viability of nonculturable Escherichia coli and Vibrio cholerae in the estuarine and marine environment. Microb. Ecol. 1982, 8, 313-323. [CrossRef] [PubMed]

13. Robben, C.; Witte, A.K.; Schoder, D.; Stessl, B.; Rossmanith, P.; Mester, P. A fast and easy ATP-based approach enables MIC testing for non-resuscitating VBNC pathogens. Front. Microbiol. 2019, 10, 1365. [CrossRef] [PubMed]

14. Desneux, J.; Biscuit, A.; Picard, S.; Pourcher, A.-M. Fate of viable but non-culturable Listeria monocytogenes in pig manure microcosms. Front. Microbiol. 2016, 7, 245. [CrossRef] [PubMed]

15. Afari, G.K.; Hung, Y.-C. Detection and verification of the viable but nonculturable (VBNC) state of Escherichia coli O157:H7 and Listeria monocytogenes using flow cytometry and standard plating. J. Food Sci. 2018, 83, 1913-1920. [CrossRef] [PubMed]

16. Berney, M.; Weilenmann, H.-U.; Egli, T. Flow-cytometric study of vital cellular functions in Escherichia coli during solar disinfection (SODIS). Microbiology 2006, 152, 1719-1729. [CrossRef] [PubMed] 
17. Morishige, Y.; Fujimori, K.; Amano, F. Use of flow cytometry for quantitative analysis of metabolism of viable but non-culturable (VBNC) Salmonella. Biol. Pharm. Bull. 2015, 38, 1255-1264. [CrossRef]

18. Merchel Piovesan Pereira, B.; Tagkopoulos, I. Benzalkonium chlorides: Uses, regulatory status, and microbial resistance. Appl. Environ. Microbiol. 2019, 85. [CrossRef]

19. To, M.S.; Favrin, S.; Romanova, N.; Griffiths, M.W. Postadaptational resistance to benzalkonium chloride and subsequent physicochemical modifications of Listeria monocytogenes. Appl. Env. Microbiol. 2002, 68, 5258-5264. [CrossRef]

20. Wessels, S.; Ingmer, H. Modes of action of three disinfectant active substances: A review. Regul. Toxicol. Pharmacol. 2013, 67, 456-467. [CrossRef]

21. Romanova, N.A.; Wolffs, P.F.G.; Brovko, L.Y.; Griffiths, M.W. Role of efflux pumps in adaptation and resistance of Listeria monocytogenes to benzalkonium chloride. Appl. Env. Microbiol. 2006, 72, 3498-3503. [CrossRef]

22. Yu, T.; Jiang, X.; Zhang, Y.; Ji, S.; Gao, W.; Shi, L. Effect of benzalkonium chloride adaptation on sensitivity to antimicrobial agents and tolerance to environmental stresses in Listeria monocytogenes. Front. Microbiol. 2018, 9, 2906. [CrossRef] [PubMed]

23. Roedel, A.; Dieckmann, R.; Brendebach, H.; Hammerl, J.A.; Kleta, S.; Noll, M.; Al Dahouk, S.; Vincze, S. Biocide tolerant Listeria monocytogenes isolates from German food production plants do not show cross-resistance to clinically relevant antibiotics. Appl. Environ. Microbiol. 2019. [CrossRef]

24. DIN EN ISO 11290. Mikrobiologie der Lebensmittelkette- Horizontales Verfahren für den Nachweis und die Zählung von Listeria monocytogenes und von Listeria spp.- Teil 1: Nachweisverfahren (ISO 11290-1:2017); Deutsche Fassung EN ISO 11290-1:2017; Beuth Verlag GmbH: Berlin, Germany.

25. Noll, M.; Kleta, S.; Al Dahouk, S. Antibiotic susceptibility of 259 Listeria monocytogenes strains isolated from food, food-processing plants and human samples in Germany. J. Infect. Public Health 2018, 11, 572-577. [CrossRef] [PubMed]

26. R Core Team v. 3.3.3. R: A Language and Environment for Statistical Computing; R Core Team v. 3.3.3: Vienna, Austria, 2017.

27. Lundén, J.; Autio, T.; Markkula, A.; Hellström, S.; Korkeala, H. Adaptive and cross-adaptive responses of persistent and non-persistent Listeria monocytogenes strains to disinfectants. Int. J. Food Microbiol. 2003, 82, 265-272. [CrossRef]

28. Aase, B.; Sundheim, G.; Langsrud, S.; Rørvik, L.M. Occurrence of and a possible mechanism for resistance to a quaternary ammonium compound in Listeria monocytogenes. Int. J. Food Microbiol. 2000, 62, 57-63. [CrossRef]

29. Rakic-Martinez, M.; Drevets, D.A.; Dutta, V.; Katic, V.; Kathariou, S. Listeria monocytogenes strains selected on ciprofloxacin or the disinfectant benzalkonium chloride exhibit reduced susceptibility to ciprofloxacin, gentamicin, benzalkonium chloride, and other toxic compounds. Appl. Env. Microbiol. 2011, 77, 8714-8721. [CrossRef] [PubMed]

30. Léonard, L.; Bouarab Chibane, L.; Ouled Bouhedda, B.; Degraeve, P.; Oulahal, N. Recent advances on multi-parameter flow cytometry to characterize antimicrobial treatments. Front. Microbiol. 2016, 7, 1225. [CrossRef]

31. Li, L.; Mendis, N.; Trigui, H.; Oliver, J.D.; Faucher, S.P. The importance of the viable but non-culturable state in human bacterial pathogens. Front. Microbiol. 2014, 5, 258. [CrossRef]

32. Highmore, C.J.; Warner, J.C.; Rothwell, S.D.; Wilks, S.A.; Keevil, C.W. Viable-but-nonculturable Listeria monocytogenes and Salmonella enterica serovar Thompson induced by chlorine stress remain infectious. MBio 2018, 9. [CrossRef]

(C) 2020 by the authors. Licensee MDPI, Basel, Switzerland. This article is an open access article distributed under the terms and conditions of the Creative Commons Attribution (CC BY) license (http://creativecommons.org/licenses/by/4.0/). 